\title{
Structural insights into DNA recognition by AimR of the arbitrium communication system in the SPbeta phage
}

\author{
Zeyuan Guan', Kai Pei', Jing Wang ${ }^{1}$, Yongqing Cui', Xiang Zhu' ${ }^{1}$ Xiang Su', Yuanbao Zhou', Delin Zhang ${ }^{1}$, \\ Chun Tang ${ }^{2}$, Ping Yin ${ }^{1}$, Zhu Liu (D) ${ }^{1}$ and Tingting Zou (1) ${ }^{3}$
}

\begin{abstract}
A newly identified arbitrium communication system regulates the lysis-to-lysogeny decision in a Bacillus bacteriophage. This system contains an arbitrium hexapeptide as a signal, the cellular receptor AimR, and the lysogenic negative regulator AimX. AimR specifically targets the downstream DNA to activate aimX gene expression. The arbitrium peptide binds to AimR, inhibiting its DNA-binding to promote phage lysogeny. Recently, we and other groups have elucidated how arbitrium peptide sensed by AimR. However, the molecular mechanisms of DNA recognition by AimR and the regulation of its DNA-binding activity by the peptide remain largely unknown. Here, we report the crystal structure of the AimR-DNA complex at $2.1 \AA$ resolution. The N-terminal HTH motif recognizes the palindromic DNA sequence, buttressed by interactions between positively charged residues and the DNA phosphate groups. The DNA-bound AimR assembles a more closed dimer than the peptide-bound form. Single-molecule FRET and crosslinking assays revealed that the AimR protein samples both open and closed conformations in solution. Arbitrium peptide binding induces a closed-to-open conformational change of AimR, eliminating DNA targeting. Our structural and functional analysis provides new insights into the DNA recognition mechanism of AimR and its regulation by the arbitrium peptide in the context of phage lysis-lysogeny decisions.
\end{abstract}

\section{Introduction}

Gram-positive bacteria communicate with each other via secreted peptide signals to adapt to the environment by regulating gene expression related to bacterial sporulation, biofilm formation, the virulence activation process, etc. ${ }^{1-7}$. Typically, 5- to 10-amino acid signal peptides are sensed by receptors, leading to allosteric regulation of the receptors' activity. In the quorum-sensing system, the receptors

\footnotetext{
Correspondence: Tingting Zou (zoutingting@mail.hzau.edu.cn)

${ }^{1}$ National Key Laboratory of Crop Genetic Improvement and National Centre of Plant Gene Research, Huazhong Agricultural University, Wuhan 430070 Hubei, China

${ }^{2}$ CAS Key Laboratory of Magnetic Resonance in Biological Systems, State Key Laboratory of Magnetic Resonance and Atomic Molecular Physics, and National Center for Magnetic Resonance at Wuhan, Wuhan Institute of Physics and Mathematics, Chinese Academy of Sciences, Wuhan 430071 Hubei Province, China

Full list of author information is available at the end of the article.

These authors contributed equally: Zeyuan Guan, Kai Pei
}

are Rap-Rgg-NprR-PlcR-PrgX (RRNPP) members, which employ an N-terminal domain to bind to target DNA or partner proteins and a $\mathrm{C}$-terminal tetratricopeptide repeat (TPR) domain to coordinate the peptide. The molecular mechanisms by which peptides regulate the activities of RRNPP proteins are well studied ${ }^{8-10}$.

Recently, in Bacillus phages, a peptide communication system named the arbitrium system was identified that plays an essential role in lysis-lysogeny decisions during infection of Bacillus host cells ${ }^{11-14}$. This system requires the arbitrium hexapeptide to bind to its cellular receptor AimR to regulate transcription of the lysogeny negative regulator gene aimX. After infecting Bacillus host cells, the phage produces the precursors of signal peptides encoded by the aimP gene. The premature peptides are secreted to the extracellular environment and cleaved by bacterial extracellular proteases to generate the mature

\section{(c) The Author(s) 2019}

(c) (i) Open Access This article is licensed under a Creative Commons Attribution 4.0 International License, which permits use, sharing, adaptation, distribution and reproduction in any medium or format, as long as you give appropriate credit to the original author(s) and the source, provide a link to the Creative Commons license, and indicate if changes were made. The images or other third party material in this article are included in the article's Creative Commons license, unless indicated otherwise in a credit line to the material. If material is not included in the article's Creative Commons license and your intended use is not permitted by statutory regulation or exceeds the permitted use, you will need to obtain permission directly from the copyright holder. To view a copy of this license, visit http://creativecommons.org/licenses/by/4.0/. 
hexapeptide. The secreted peptides are imported into the host cell through an oligopeptide permease transporter and then bind to the AimR receptor, which functions as a transcription factor. Consequently, peptide-bound AimR loses its DNA-binding activity. This signal enables phage integration into the Bacillus genome as a prophage ${ }^{11}$.

AimR is composed of two domains, a $\mathrm{N}$-terminal domain that is responsible for DNA binding and a Cterminal domain that specifically recognizes the arbitrium peptide. In a previous study, we reported the structures of AimR with and without the arbitrium peptide from SPbeta group phages ${ }^{15}$. The overall structure of AimR is similar to that of RRNPP family proteins. The C-terminal domain coordinates the arbitrium peptide GMPRGA via its four atypical TPR repeats. Furthermore, we biochemically demonstrated that AimR specifically targets a 51-bp DNA sequence downstream of the aimP gene, and its DNA-binding activity is decreased upon peptide binding. Interestingly, both the apo form and peptidebound form of AimR exhibit dimer formation mediated through the last C-terminal capping helix. Only subtle conformational changes were observed between apo- and peptide-bound AimR. Similar results were obtained by other groups ${ }^{16,17}$. Despite this progress, it remains unknown whether DNA-bound AimR adopts a distinct conformation, whether the peptide inhibits these conformational changes and, if so, how this might happen.

Here, we report the complex structure of the AimR protein and cognate DNA. Dimeric AimR binds to a palindromic DNA via two interaction areas. The $\mathrm{N}$ terminus of AimR exhibits a classic HTH motif that specifically recognizes a trinucleotide inverted repeat. In addition, a patch of positively charged residues from the C-terminal TPR motifs coordinate the DNA phosphate groups to reinforce the interactions. Substitutions of the key DNA recognition residues are unable to initiate phage lysogeny in vivo. Compared with the structures of the apo form and peptide-bound form, the conformation of DNAbound AimR becomes more closed, generating a second dimer interface. Furthermore, by single-molecule fluorescence resonance energy transfer (smFRET) and crosslinking assays, we found that in solution, the AimR protein samples two conformational states, a closed state and an open state. In the presence of the arbitrium peptide, the population of the open state is increased, while upon binding to DNA, the majority of AimR remains in the closed state, in line with the structural observations. Taken together, the crystal structures and dynamic structural studies not only reveal the molecular mechanism by which the arbitrium peptide regulates the DNAbinding activity of the AimR protein from the SPbeta phage in lysis-lysogeny decisions but also serve as a framework for investigating the ligand regulation functions of proteins in the RRNPP family.

\section{Results}

\section{Crystal structure of the SPbeta AimR-DNA complex}

To understand how AimR recognizes the DNA sequence, we reconstituted and crystallized a binary complex between the AimR protein and the cognate DNA fragment from the SPbeta group phage. Previously, we identified a 51 bp DNA segment (locus 77704-77754 downstream of the aimP gene in the SPbeta phage) that binds the AimR protein with a dissociation constant $\left(K_{\mathrm{d}}\right)$ of $101 \mathrm{nM}$ through electrophoretic mobility shift assays (EMSA) ${ }^{15}$. The DNA fragment contains a $31 \mathrm{bp}$ palindromic sequence $\left(5^{\prime}\right.$ ACTTAAATATTAGGTTTTAATAACATCTAGT 3', locus 77710-77740 in the SPbeta phage genome) (Supplementary Fig. S1). The 31 bp fragment retains the ability to bind AimR (see results below). Deletion of one or more nucleotides results in a notably decreased dissociation constant. After numerous crystallization trials for AimR with different DNA fragments, we finally determined the structure of full-length AimR in the presence of the $31 \mathrm{bp}$ DNA at $2.10 \AA$ resolution by molecular replacement. In the crystals, there is one AimR dimer in each asymmetrical unit. Most amino acids and nucleotides are assigned to the electron density map. Each AimR protomer consists of an $\mathrm{N}$-terminal DNA-binding domain (DBD, residues 1-48) and a C-terminal regulatory domain (CTD, residues 49-386). The DBD is a typical HTH DNA-binding motif containing a three-helix bundle $\left(\alpha 1^{\prime}, \alpha 2^{\prime}\right.$, and $\left.\alpha 3^{\prime}\right)$ (Fig. 1a, d), which is conserved among the Bacillus phages (Supplementary Fig. S2). The CTD is composed of $20 \alpha$-helices that form a right-handed superhelical assembly. In the apoand peptide-bound form, the AimR dimer exhibits an inverted trapezoid-like fold. The last C-terminal capping helices from two AimR molecules undergo dimerization via a network of van der Waals interactions. In contrast, the DNA-bound AimR dimer has two interaction faces (Fig. 1a). One face is identical to that of the apo- and peptide-bound form. The other face is generated by the residues Glu132, Tyr161, and Asn166 from helix 6, helix 7, and loop 7, respectively, of each protomer. These residues form hydrogen bonds with each other (Fig. 1c).

\section{DNA recognition mode}

The interaction between AimR and DNA is primarily mediated by the $\mathrm{N}$-terminal area, including extensive hydrogen bonds and ionic interactions, giving rise to two major interfaces (approximately $1300 \AA$ A , Fig. 1). First, each protomer of the AimR dimer symmetrically binds to the major grooves of the DNA fragment through its DBD domain (Fig. 1a). The recognition helix $\alpha 3^{\prime}$ from each DBD domain is oriented to the DNA axis and specifically interacts with bases from the major groove via the side chains of residues Asn30 and Asn32 (Fig. 2b). Considering protomer A, the side chains of Asn30 and Asn32 form hydrogen bonds with base A29' and G30' on the antisense 


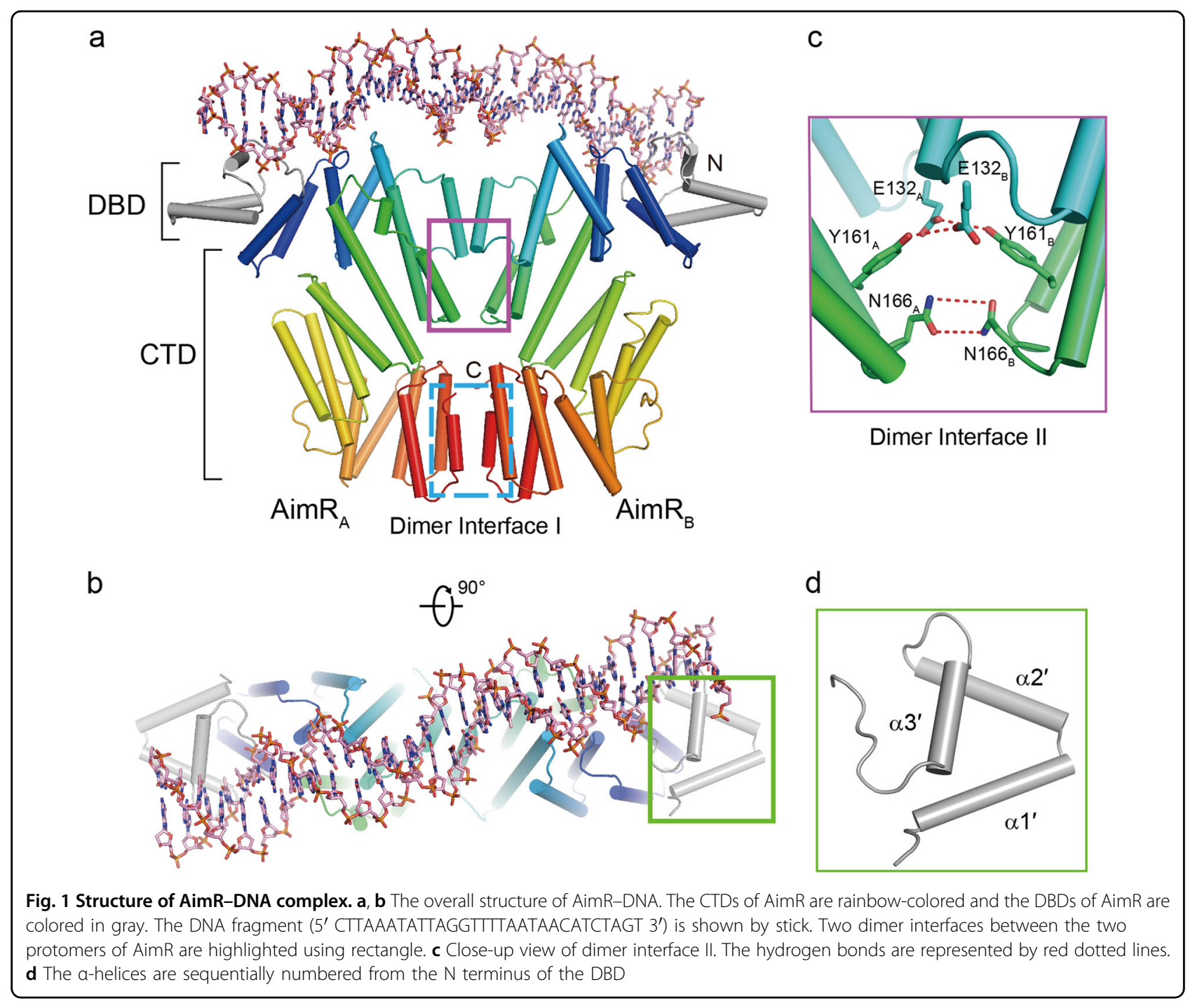

strand (Fig. 2a, b). The side chains of Asn30 and Asn32 from protomer $B$ establish base-specific interactions with base T31 on the sense strand (Fig. 2a, b). Buttressing the hydrogen bonds, ten residues (Lys29, Lys43, Thr44, Asn46, Lys77, Thr78, Lys79, Arg82, Asn109, and Lys145) in the positively charged patches contribute coordination of the backbone phosphates of T9, T10, T11, A20, T28, $\mathrm{A} 29, \mathrm{G} 30, \mathrm{~T}^{\prime}, \mathrm{G} 8^{\prime}, \mathrm{T} 9^{\prime}, \mathrm{T} 26^{\prime}, \mathrm{T} 27^{\prime}$, and $\mathrm{A} 29^{\prime}$, constituting the second interface (Fig. 2a, b). These structural observations are consistent with our previous biochemical analysis $^{15}$. The whole DNA fragment displays the characteristic shape of a right-handed B-form nucleic acid structure with average global roll and twist angles of $-1.14^{\circ}$ and $36.09^{\circ}$, respectively. Whereas the major groove width at the recognition site is widened to $18.54 \AA$, and the average minor groove width is narrowed to $10.35 \AA$, demonstrating the conformational changes of DNA upon AimR binding (Supplementary Fig. S3).
To verify the base-recognition specificity observed in the AimR-DNA complex, we mutated the palindromic sequence $\left(5^{\prime}\right.$ ACT........AGT $\left.3^{\prime}\right)$ one by one to assess the binding affinities of AimR (Fig. $2 \mathrm{c}$ and Supplementary Fig. S4). AimR binds to DNA with an apparent dissociation constant $\left(K_{\mathrm{d}}\right)$ of $100.5 \pm 27.6 \mathrm{nM}$, consistent with our previous study ${ }^{15}$. The most significant effect of base substitution was observed at $\mathrm{C} 2\left(\mathrm{G} 30^{\prime}\right)$, and mutation of $\mathrm{C} 2$ to adenine, guanine, and thymine reduced the AimR DNA binding activities by approximately 8-, 9-, and 42fold, respectively. A1T/T31'A and A1G/T31'C substitution lowered the AimR-binding affinity by approximately 7- and 19-fold, respectively, while other mutations had little influence on the AimR-DNA interaction (Supplementary Fig. S4). Together with the structural observations, the DNA mutational analysis suggests that the adenine and cytosine bases at the palindromic repeats are essential for DNA recognition by AimR. 


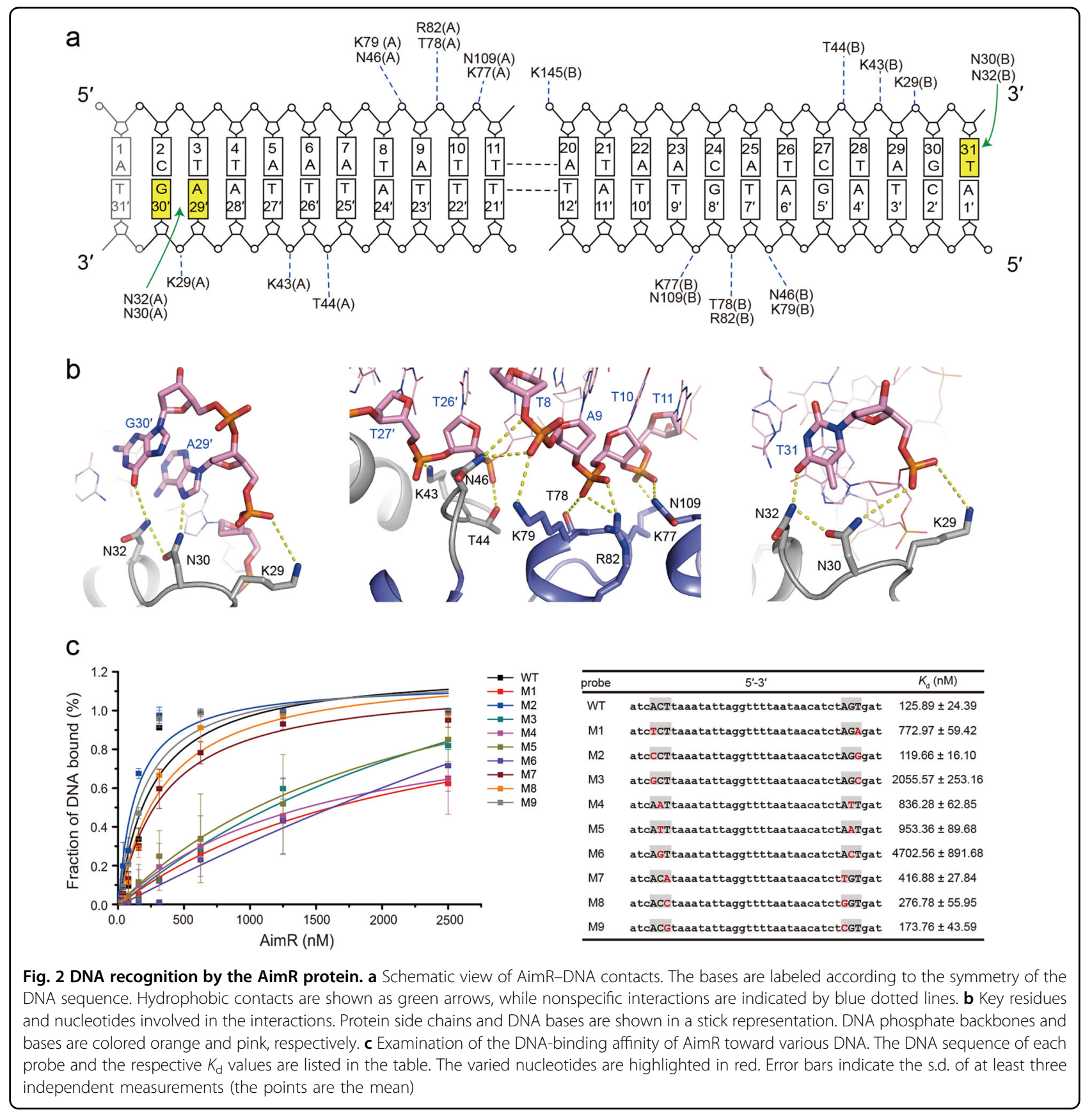

\section{Functional implications of the DNA-binding residues of AimR}

The importance of residues involved in DNA recognition is supported by mutational analysis. As anticipated, AimR binds to its cognate DNA; the arbitrium peptide disrupts this interaction, but the unrelated control peptide does not (Fig. 3a, left upper panel). Several mutants, K29D, N32A, K43D, K79D, R82D, N109D, and K145D, show notable weak DNA-binding activity, but N30A, T44D, N46D, K77D, and T78D retain activity comparable to that of the control (Fig. 3a and Supplementary Fig. S5). As a control, we also mutated the unrelated Lys120 to Asp, with no detectable effects on DNA binding (Fig. 3a, left upper panel). All of these mutant proteins exhibited behavior similar to that of wild-type AimR via gel filtration (Supplementary Fig. S6). Moreover, we measured the DNA-binding affinities of these AimR mutations (Supplementary Fig. S5). AimR N32A showed a significant decrease in DNA-binding activity, with $K_{\mathrm{d}}=6824.02 \pm$ $2250.58 \mathrm{nM}$. In addition, T44D reduced the DNA-binding 


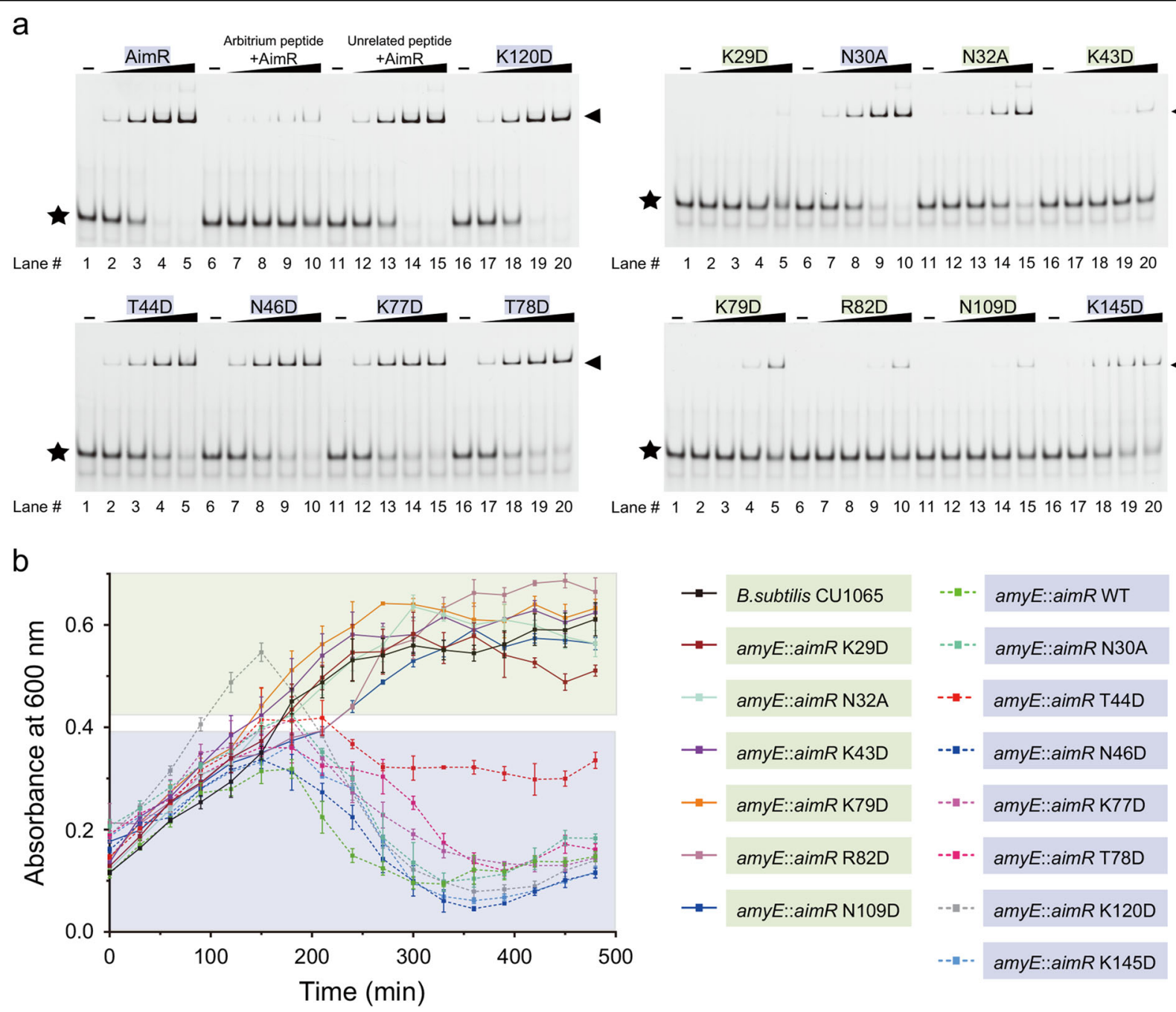

Fig. 3 Effect of AimR mutations on DNA binding and infection dynamics of SPbeta phage. a DNA-binding activities of wild-type AimR and AimR mutants were examined. The AimR concentrations in lanes $1-5$ were $0,0.008,0.04,0.2$, and $1 \mu \mathrm{M}$, respectively. The concentration of the $31 \mathrm{bp}$ DNA fragment was $20 \mathrm{nM}$. The arbitrium peptide (GMPRGA) and an unrelated peptide (GFGHGA) were added as controls. AimR-DNA complex is indicated by a black arrowhead, and free DNA is indicated by a black asterisk. $\mathbf{b}$ Effect of AimR mutations on the infection dynamics of SPbeta. Growth curves of B. subtilis strain CU1065 infected with SPbeta, or that of B. subtilis strain CU1065 (amyE::aimR WT, K29D, N30A, N32A, K43D, T44D, N46D, K77D, T78D, K79D, R82D, N109D, K145D, or K120D) infected with SPbeta $\triangle$ aimR at MOI $=0.001$. Data represent an average of three biological replicates, and each with three technical replicates. Error bars indicate the s.d. of at least three independent measurements (the points are the mean)

affinity of AimR by 11-fold, but four mutations (N30A, N46D K77D, and T78D) had little impact on DNA targeting (Supplementary Fig. S5).

We further assessed the effect of DNA-binding mutations on the lysis-lysogeny decision during SPbeta phage infection. First, we constructed the aimR deletion SPbeta phage $(\triangle a i m R)$ to examine the infection dynamics in the host bacteria (Bacillus subtilis CU1065) or aimR-generecovered cells. After infection with SPbeta $\triangle a i m R$, the bacteria continued to grow (Fig. 3b, black curve), but the cells that overexpressed the AimR protein (B. subtilis CU1065, amyE::aimR) lysed within $3 \mathrm{~h}$ (light green curve). Next, we prepared a dozen strains that integrated aimR mutant genes into the host genome. The mutants with DNA-binding affinities similar to those of the wild-type AimR protein had similar lysis curves, except for K145D. However, no induced lysis was observed in B. subtilis CU1065 (amyE::aimR K29D, N32A, K43D, K79D, R82D, or N109D) (Fig. 3b). Overall, structural and functional analysis demonstrates that these residues play an essential role in DNA binding.

\section{The DNA-bound AimR dimer exhibits a closed conformation}

In our previous reported structures of apo- and peptidebound AimR, we were unable to trace the $\mathrm{N}$-terminal 
DBD structure due to the poor electronic densities ${ }^{15}$. In this study, we reoptimized the crystals and collected new datasets for AimR with or without the peptide. Crystal structure determination was performed by molecular replacement using the DNA-bound DBD of AimR as the template. Finally, we traced the density of the DBD for AimR with or without the peptide (Supplementary Fig. S7 and Table 1). Although both the apo- and peptide-bound AimR structures exhibited nearly identical structures with an average root mean square deviation of $1.459 \AA$ over an average of 776 aligned $C \alpha$ atoms, the DBD of apo- or peptide-bound AimR exhibited a more flexible conformation than the DNA-bound AimR (Supplementary Fig. S7a-c).

Interestingly, alignment of DNA-bound AimR with apoor peptide-bound AimR revealed that the DNA-bound AimR exhibits a strongly closed conformation. The distance between the two aspartic acid residues in the inner cavity, D15 of AimR $R_{A}$ and D15 of $A i m R_{B}$, is approximately $125 \AA$ in apo- or peptide-bound AimR. However, the distance between these two aspartic acid residues is nearly $110 \AA$ in the AimR-DNA complex. A structure alteration also occurs at the C-terminal domain of AimR in the complex, with the side measurement changed to $\sim 57 \AA$ in the dimeric AimR ( $50 \AA$ in the apo form AimR). In addition, the DBD motif of $\mathrm{AimR}_{\mathrm{B}}$ shows conformational variation, with a rotation of approximately $15^{\circ}$ towards the protomer AimR $_{\mathrm{A}}$ (Fig. 4). These structural analyses suggest that AimR has distinct conformations, here, named the open and closed conformations, upon peptide or DNA binding.

\section{The arbitrium peptide stabilizes the AimR dimer in the open state}

To characterize how the conformation of AimR changes in solution, we performed smFRET analysis. For fluorescent probe labeling, we mutated all six solvent-exposed cysteines to serines (C71S/C107S/C213S/C275S/C304S/ $\mathrm{C} 347 \mathrm{~S}$ ) and generated an additional V129C mutation to enable specific dye labeling through thiol-maleimide chemical conjugation (Fig. 5a, b). The smFRET data clearly showed that the FRET profile of AimR can be fitted to two FRET species. The low- and high-FRET efficiencies are centered at $30 \%$ and $60 \%$, with respective populations of $\sim 43 \%$ and $\sim 57 \%$ (Fig. 5 c, g). Hence, in solution, AimR alone exists in two dynamic conformational states that correspond to the open and closed conformations according to the low- and high-FRET efficiencies.

To assess the dynamic conformational states for target binding, we titrated the arbitrium peptide and the DNA into the solution and monitored the smFRET profile changes. The arbitrium peptide enriched the low-FRET species, while the high-FRET population was reduced (Fig. $5 \mathrm{c}-\mathrm{f}$ ). However, an unrelated peptide had no effects on the FRET profile (Supplementary Fig. S8d). In contrast, the high-FRET species were selectively enriched by the cognate DNA at the expense of the low-FRET species (Fig. $5 g-j)$. Thus, the open conformation accounts for peptide binding, while the closed conformation accounts for DNA binding. Confirming this conclusion, the smFRET measured dye-dye distances in the two conformational states were consistent with the theoretically calculated distances in the crystal structures (Supplementary Fig. S9). The FRET species were selectively enriched with no apparent FRET efficiency shift during peptide or DNA titration, implying that AimR recognizes the arbitrium peptide and DNA via a conformational selection mechanism.

To verify whether AimR indeed exists as two distinct states in solution, we employed a disulfide bond-mediated crosslinking strategy (Fig. 6a). Structural analysis showed that the distance between Asn166 of $\operatorname{AimR}_{A}$ and $\operatorname{AimR}_{B}$ is 3.5-4 $\AA$ in the closed conformation (Fig. 1b) but more than $25 \AA$ in the open conformation. We generated a cysteine-substitution mutant (AimR N166C). Upon ophenanthroline copper treatment, AimR showed a stable homodimer, indicating disulfide bond formation (Fig. 6b, left upper panel). The crosslinked AimR (N166C) and wild-type AimR showed similar behavior according to the nearly identical elution volumes on size-exclusion chromatography (Supplementary Fig. S10). In the presence of target DNA, AimR (N166C) also presented as a stable homodimer (Fig. 6b, right upper panel). However, AimR N166C could not be well crosslinked upon arbitrium peptide incubation, and the unrelated peptide had little effect. These results suggest that AimR exists in the closed and open conformations in solution and converts to the open conformation in the presence of the arbitrium peptide.

We hypothesized that the arbitrium peptide is able to stabilize AimR in the open state even after exposure to DNA. To test this scenario, we performed a completion experiment at the single-molecule level. Before binding saturation, $1 \mu \mathrm{M}$ DNA increased the population of the high-FRET species of AimR from 56.7 to $67.6 \%$ (Fig. 5g, i). However, the addition of $1 \mu \mathrm{M}$ arbitrium peptide dramatically increased the low-FRET species, while the highFRET species was reduced to 6.1\% (Supplementary Fig. $\mathrm{S} 8 \mathrm{a}-\mathrm{c})$. These data suggested that the arbitrium peptide selectively enriches and stabilizes the preexisting open conformation of AimR, while the closed conformation is converted to the open conformation, leading to DNA dissociation.

\section{Discussion}

In the phage arbitrium communication system, the AimR protein binds to the arbitrium peptide to lose its DNA-binding activity and subsequently regulates gene expression to determine the phage lysis-lysogeny 
Table 1 Statistics of data collection and refinement

\begin{tabular}{|c|c|c|c|}
\hline Structure & AimR (PDB: 6JG5) & AimR-peptide (PDB: 6JG9) & AimR-DNA (PDB: 6JG8) \\
\hline \multicolumn{4}{|l|}{ Data collection } \\
\hline Space group & $P 2,2,2$ & $P 2,2,2$ & $P 4_{1}$ \\
\hline \multicolumn{4}{|l|}{ Unit cell dimensions } \\
\hline$a, b, c(\AA)$ & $33.49,115.30,219.43$ & $33.59,120.93,214.0$ & $98.01,98.01,159.99$ \\
\hline$a, \beta, \gamma\left(^{\circ}\right)$ & $90,90,90$ & $90,90,90$ & $90,90,90$ \\
\hline Wavelength ( $\AA$ ) & 0.9792 & 0.9778 & 0.9792 \\
\hline Resolution $(\AA ̊)$ & $45-2.22(2.29-2.22)$ & $45-2.0(2.05-2.0)$ & $45-2.1(2.13-2.10)$ \\
\hline$R_{\text {merge }}(\%)$ & $10.9(34.1)$ & $7.1(38.9)$ & $4.1(68.9)$ \\
\hline $1 / \sigma()$ & $10.9(4.9)$ & $17.8(4.2)$ & $23.4(3.1)$ \\
\hline Completeness (\%) & $99.1(96.0)$ & $99.8(96.2)$ & $99.7(98.5)$ \\
\hline Number of measured reflections & 276,186 & 396,286 & 600,917 \\
\hline Number of unique reflections & 42,901 & 60,685 & 87,895 \\
\hline Redundancy & $6.4(6.2)$ & $6.5(6.2)$ & $6.8(7.0)$ \\
\hline Wilson $B$ factor $\left(\AA^{2}\right)$ & 24.9 & 23.8 & 44.4 \\
\hline \multicolumn{4}{|l|}{ Refinement } \\
\hline$R_{\text {work }} / R_{\text {free }}(\%)$ & $19.62 / 23.94$ & $21.35 / 24.88$ & $21.06 / 22.30$ \\
\hline \multicolumn{4}{|l|}{ Number of atoms } \\
\hline Protein main chain & 3120 & 3116 & 3116 \\
\hline Protein side chain & 3304 & 3279 & 3313 \\
\hline Protein all atoms & 6424 & 6395 & 6429 \\
\hline Water molecules & 329 & 406 & 257 \\
\hline Other entities & 0 & 80 & 1227 \\
\hline All atoms & 6753 & 6872 & 7913 \\
\hline \multicolumn{4}{|l|}{ Average $B$ value $\left(\AA^{2}\right)$} \\
\hline Protein main chain & 36.8 & 42.1 & 54.8 \\
\hline Protein side chain & 41.6 & 46.0 & 62.4 \\
\hline Protein all atoms & 39.2 & 44.1 & 58.7 \\
\hline Water molecules & 39.8 & 25.4 & 57.3 \\
\hline Other entities & 0 & 42.9 & 79.4 \\
\hline All atoms & 39.3 & 43.8 & 61.9 \\
\hline \multicolumn{4}{|l|}{ R.M.S. deviations from ideal values } \\
\hline Bonds $(\AA)$ & 0.009 & 0.010 & 0.009 \\
\hline Angle $\left(^{\circ}\right)$ & 0.956 & 1.094 & 1.067 \\
\hline \multicolumn{4}{|l|}{ Ramachandran plot statistics (\%) } \\
\hline Most favorable & 93.2 & 94.4 & 92.1 \\
\hline Additionally allowed & 6.8 & 5.6 & 7.8 \\
\hline Generously allowed & 0 & 0 & 0.1 \\
\hline Disallowed & 0 & 0 & 0 \\
\hline
\end{tabular}

Values in parentheses are for the highest resolution shell. $R_{\text {merge }}=\left.\Sigma_{h} \Sigma_{i}\right|_{h, i}-I_{h} \mid \Sigma_{h} \Sigma_{j} l_{h, i}$ where $I_{h}$ is the mean intensity of the $i$ observations of symmetry-related reflections of $h . R=\Sigma \mid F_{\text {obs }}-F_{\text {calc }} / \Sigma F_{\text {obs }}$ where $F_{\text {calc }}$ is the calculated protein structure factor from the atomic model $\left(R_{\text {free }}\right.$ was calculated with $5 \%$ of the reflections selected) 


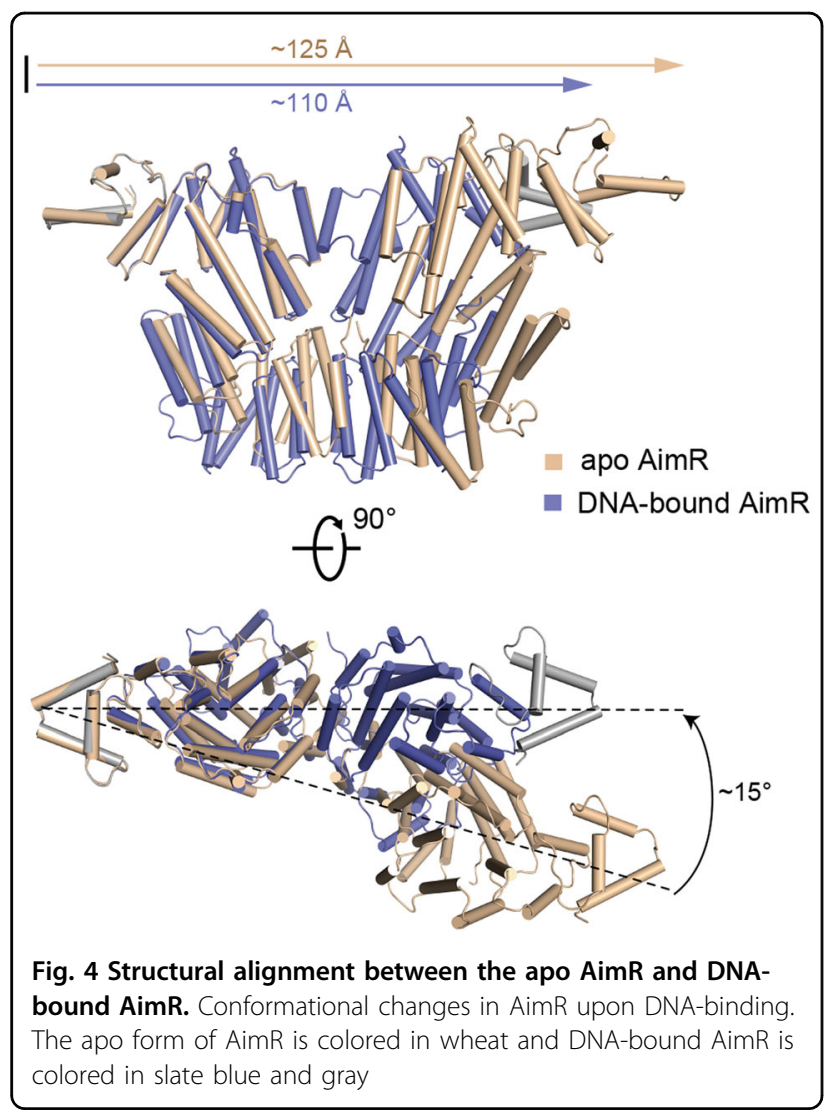

transition $^{11-13}$. Previously, we reported the structures of AimR from the SPbeta phage with and without peptide and clearly elucidated the specificity of peptide recognition, although the N-terminal DBD could not be well modeled $^{15}$. Here, we updated the apo- and peptide-bound form structures containing the DBD, although there were only subtle differences between them (Supplementary Fig. S7d). How peptide binding diminishes the DNA targeting activity of AimR must be urgently answered. In this study, we determined the crystal structure of the AimR-DNA complex, in which AimR displays a strongly closed dimeric conformation. Using smFRET assay, we observed that in solution, AimR presents at least two major conformations: open and closed states that correspond to the two obtained structures (Fig. 5c, g). Importantly, when treated by DNA titration, the population of closed AimR increased, but most of the AimR was stabilized in the open conformation after saturation with the arbitrium peptide. Thus, we proposed a peptide regulation model for the SPbeta phage arbitrium communication system. In the absence of the arbitrium peptide, dimeric AimR exhibits the dynamic open and closed conformations equally, which favor peptide and DNA binding, respectively. Upon peptide binding, AimR is trapped in the open state, and it is difficult to transition to the closed state. In turn, the peptide inhibits AimR binding to the target DNA (Fig. 7). Notably, this conformational transition inhibitory mechanism is distinct to that in the phi3T phage. The phi3T peptide is likely to disrupt the dimeric state of the AimR protein and induce a shift to the monomeric state, diminishing its DNA-binding activity ${ }^{11,16,18}$. Interestingly, the apo phi3T AimR shows a structure similar to that of SPbeta DNA-bound AimR (Supplementary Fig. S11). This observation raised an intriguing question of whether the AimR family in phages has open and closed conformations. We endeavor to answer this question by dynamic approaches in the future.

As a quorum-sensing communication system in Grampositive bacteria, RRNPP family regulators bind to signal peptides to become activated. The peptides regulate the RRNPP receptors through oligomer state transition or allosteric conformation changes. For example, binding of the peptide NprX promotes the conversion of dimeric NprR to a tetramer that specifically targets DNA to modulate gene expression ${ }^{19}$. In addition, the peptide cCF10 triggers PrgX tetramer-to-dimer dissociation and reduces the affinity of $\operatorname{PrgX}$ for the DNA-binding site of the targeted operon ${ }^{20}$. Alternatively, binding of the peptide PapR to PlcR leads to drastic conformational changes in the linker helix and N-terminal HTH domain and promotes the DNA binding of PlcR as a result ${ }^{21,22}$. Furthermore, the peptide XIP not only induces ComR dimerization but also releases the sequestered $\mathrm{HTH}$ domain to allow DNA binding during the activation process $^{23}$. These crystal structures elucidated the regulatory mechanism of the peptides. Although the structural organization of phage AimR is reminiscent of the RRNPP family regulators, how the peptide regulates receptor activity is somewhat different. The proposed conformational transition inhibition mechanism here expands our understanding of the bacterial peptide communication pathway.

Only two DNA-bound complex structures have been reported in RRNPP family regulators, the PapR-PlcR-DNA complex and the XIP-ComR-DNA complex $^{21,23}$. Here, we explored a third case concerning the structure of DNA-bound AimR, which contains a palindromic sequence ( $5^{\prime}$ ACT........AGT $\left.3^{\prime}\right)$ within a 31bp DNA fragment. On a structural basis, AimR binds to DNA as a dimer with helix $\alpha 3^{\prime}$ of the N-terminal DBD and employs the side chains of Asn30 and Asn32 to make base-specific contacts with bases T31, A29', and G30' of the palindromic sequence. Additional nonspecific contacts between some positive amino acids of AimR and the phosphate backbone of DNA further stabilize the complex. Nevertheless, mutagenesis of the palindromic sequence was unable to completely disrupt AimR DNA binding activity, as substitution mutants at position 3 of the palindromic sequence showed activity comparable to 
a

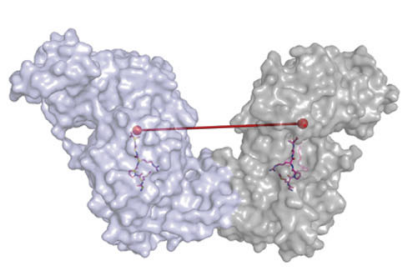

C

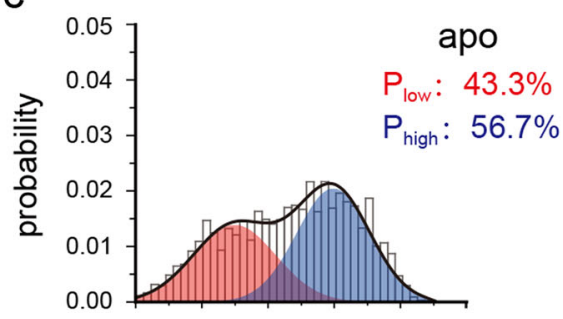

d

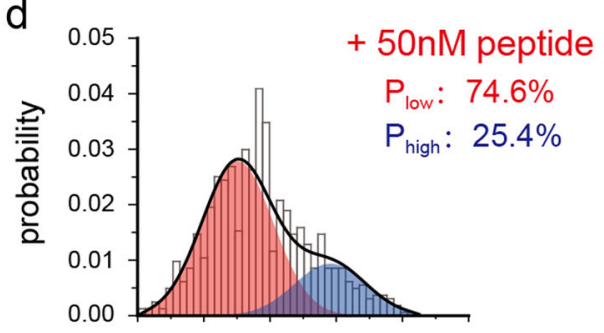

e

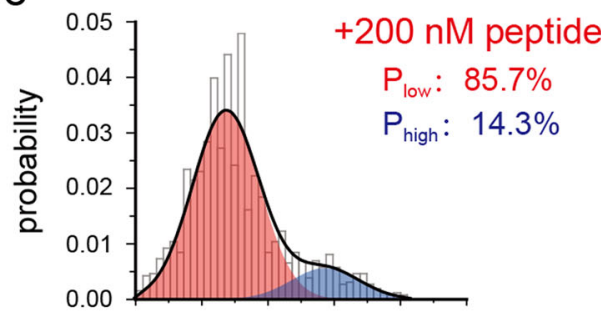

f

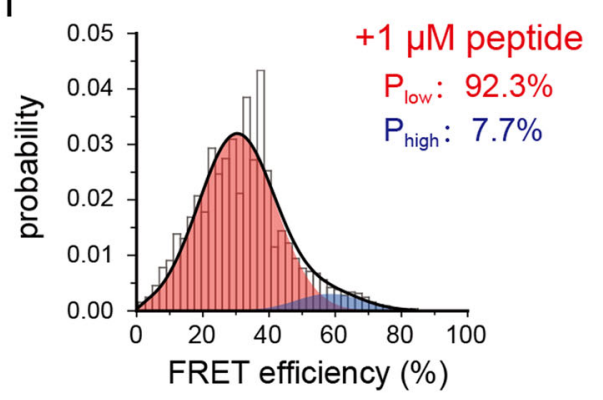

b

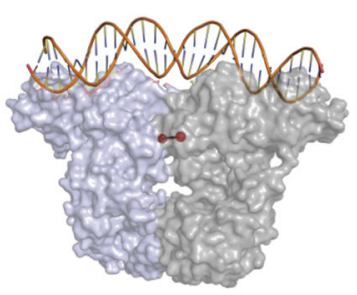

g
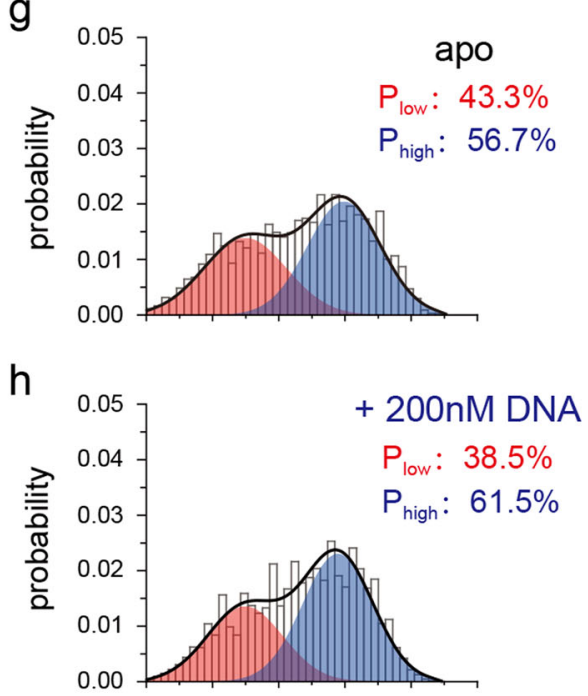

i

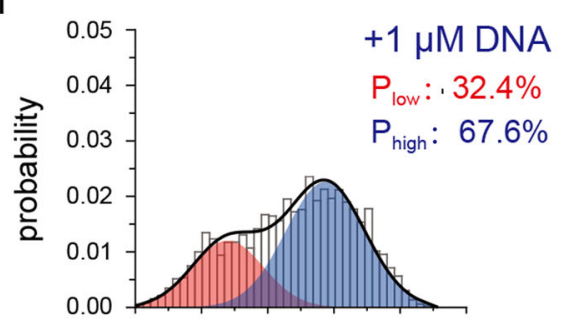

j

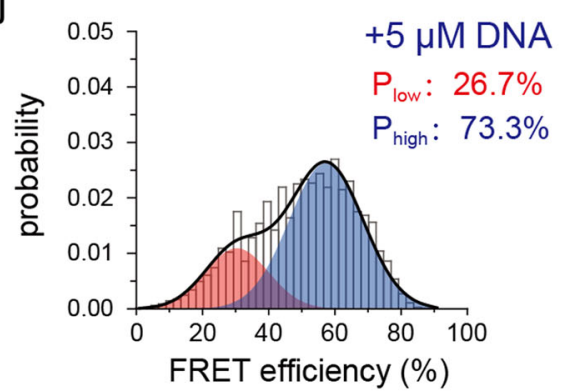

Fig. 5 AimR adopts two conformational states for targets selectively recognition. $\mathbf{a}, \mathbf{b}$ The distance between the fluorophores labeling sites in the peptide-bound AimR (red line) is longer than that in the DNA bound AimR (blue line), indicating low- and high-FRET efficiency, respectively. The Ca atoms of the Val129 are shown as red spheres, the peptide and the DNA are shown as sticks. $\mathbf{c}, \mathbf{g}$ The smFRET profile (gray histogram) of AimR can be fitted as the sum of the two FRET species (black line). The low- and high-FRET species are colored red and blue, respectively. The arbitrium peptide selectively enriches the low-FRET species ( $\mathbf{d}-\mathbf{f})$, and the DNA selectively enriches the high-FRET species (h-j). The FRET efficiency centers change little upon the ligand titrations. Note that panels $(\mathbf{c})$ and $(\mathbf{g})$ are identical in order to convenient tracking the population changes upon peptide or DNA binding 


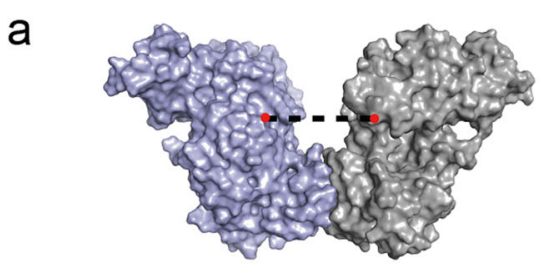

Open State

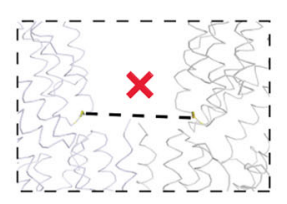

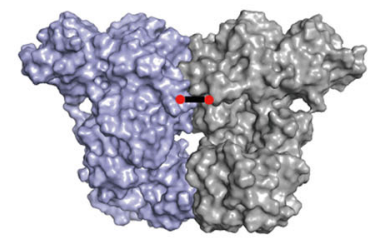

Closed State

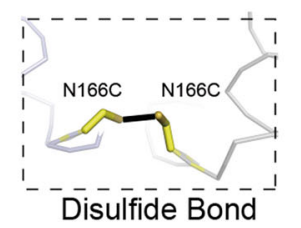

b

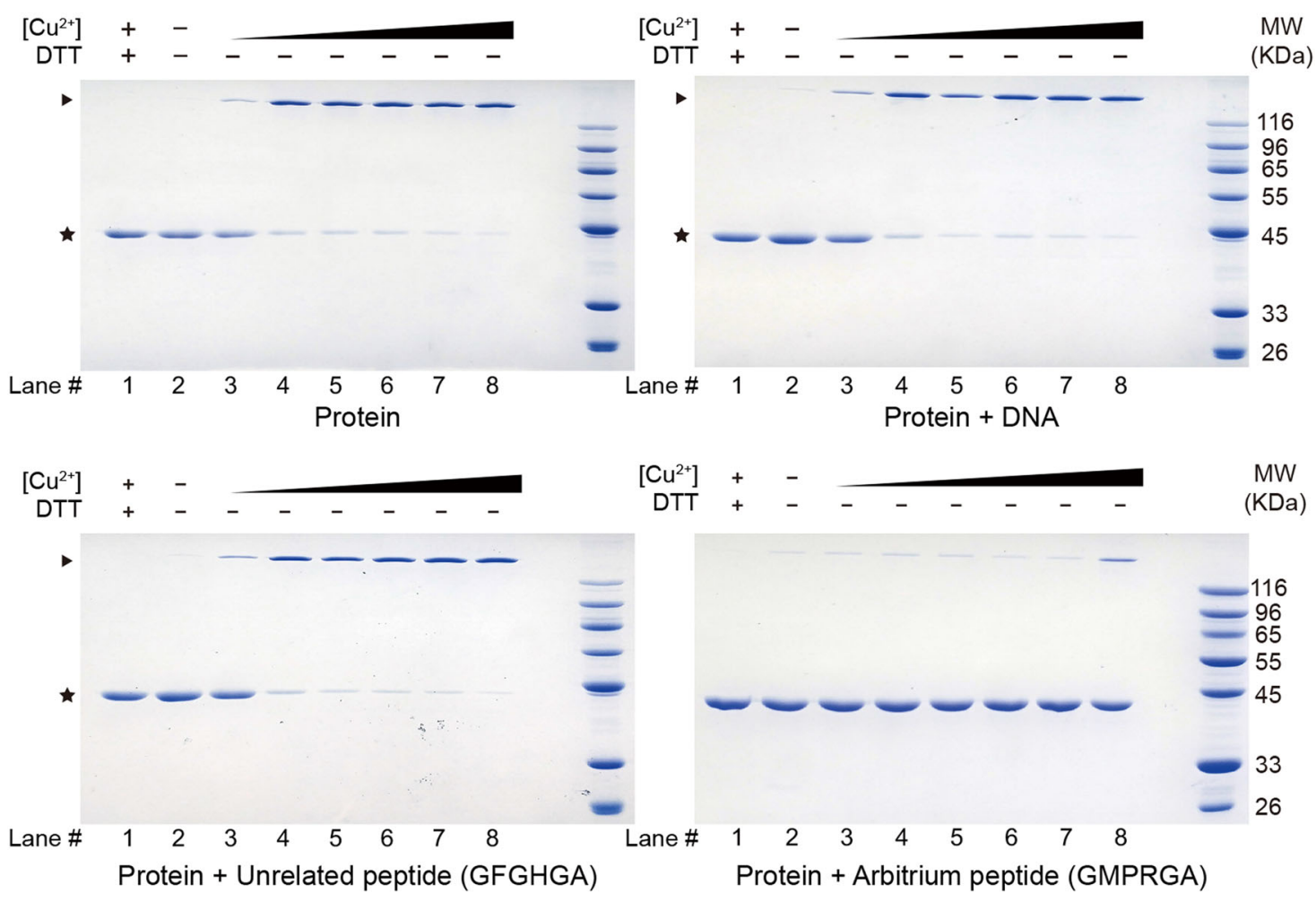

Fig. 6 The arbitrium peptide stabilizes the AimR dimer in the open state. a Dimeric interface II is mediated by residues N166 in the closed state of AimR. Asn166 of each protomer was mutated to Cys for disulfide bond formation. Both residues are labeled red. b Crosslinking of AimR-N166C. Left upper panel: Crosslinking of AimR-N166C with increasing concentrations of o-phenanthroline copper complex $\left(\mathrm{Cu}^{2+}\right)$. The reactants were subjected to nonreducing SDS-PAGE followed by Coomassie blue staining. Right upper panel: Crosslinking of AimR-N166C with increasing concentrations of $\mathrm{Cu}^{2+}$ in the presence of DNA. Left lower panel: Crosslinking of AimR-N166C with increasing concentrations of $\mathrm{Cu}^{2+}$ in the presence of an unrelated peptide. Right lower panel: Crosslinking of AimR-N166C with increasing concentrations of $\mathrm{Cu}^{2+}$ in the presence of the arbitrium peptide. The highest concentration of $\mathrm{Cu}^{2+}$ in lane 8 is $1 \mathrm{mM}$, and the concentration decreased sequentially by a 1:3 gradient from lane 8 to lane 3 . The addition of $5 \mathrm{mM}$ DTT effectively broke the disulfide bond (Lane 1)

that of the wild-type DNA (Fig. 2c). This finding raises the possibility that AimR targets similar sequences within the Bacillus genome, which hierarchically regulate the phage lysis process. The latest research explored other putative
DNA targets of AimR in vitro, but the available information is still limited ${ }^{24}$. The regulation of multiple genes by AimR during the lysis-lysogeny transition needs to be further investigated in vivo. 


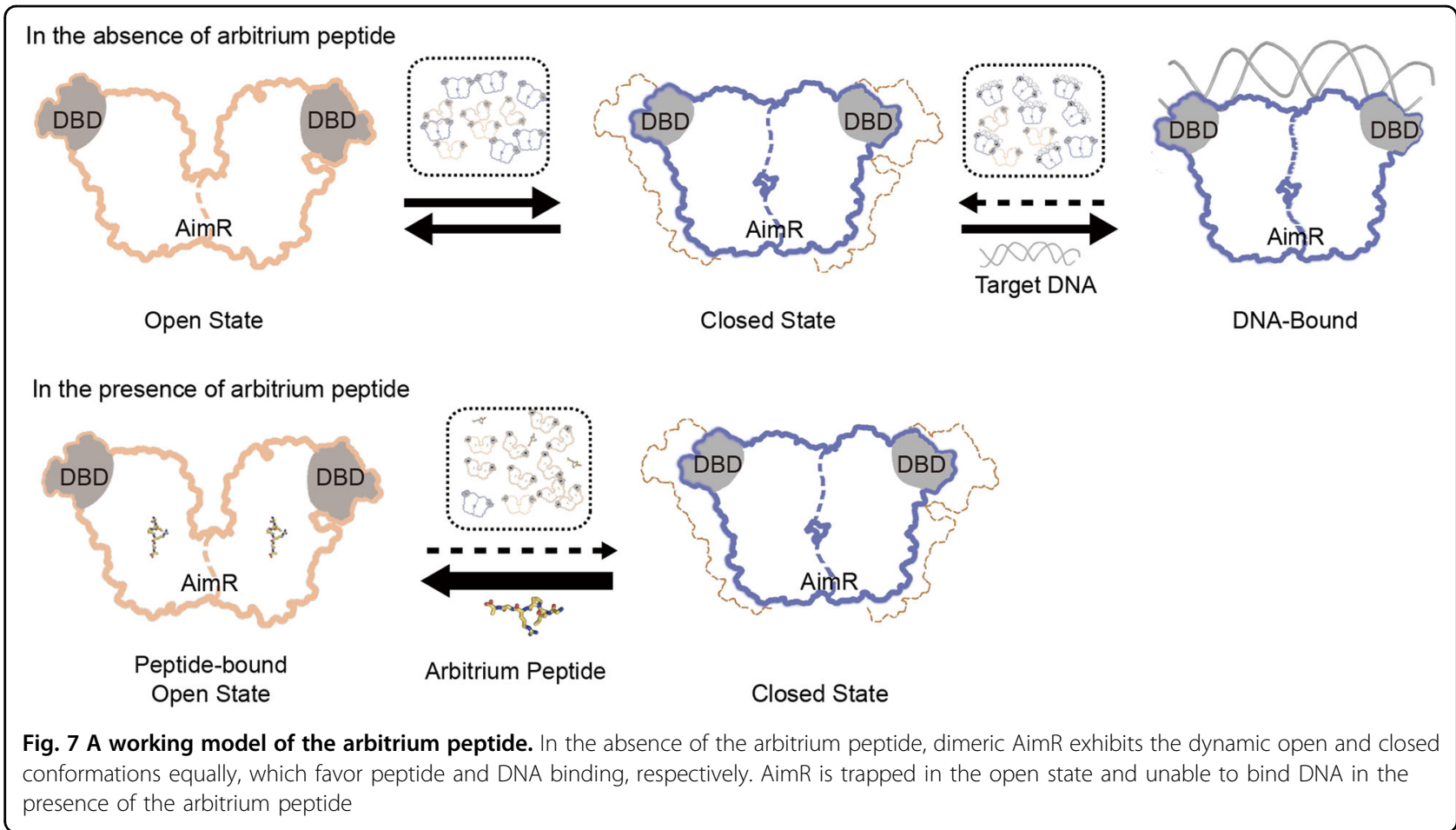

\section{Materials and methods}

\section{Bacterial strains, plasmids, and phage}

B. subtilis strain 168 (BGSCID: 1A1) and B. subtilis strain CU1065 (BGSCID: 1A100) were obtained from the Bacillus Genetic Stock Center (BGSC). Wild-type and mutant aimR genes with their own promoters were cloned into the pDG1730 vector. These plasmids were transformed into B. subtilis CU1065 and integrated into the amyE locus of the B. subtilis genome, as previously described $^{25}$. Phage SPbeta was induced from B. subtilis strain 168 using $0.5 \mu \mathrm{g} / \mathrm{ml}$ mitomycin $\mathrm{C}$ (MedChemExpress, HY-13316) for $3 \mathrm{~h}$ and was then purified and amplified in B. subtilis strain CU1065 ${ }^{26}$. The aimR deletion phage strain was generated as described previously ${ }^{15}$.

\section{Protein preparation}

The codon-optimized complementary DNA of fulllength aimR from SPbeta (GenBank: NC_001884) was subcloned into the $\mathrm{pET} 21 \mathrm{~b}$ vector (Invitrogen) with a Cterminal $8 \times$ His tag. The AimR clone was transformed into Escherichia coli strain BL21 (DE3) and induced with $0.2 \mathrm{mM}$ isopropyl $\beta$-D-thiogalactopyranoside at an absorbency $(600 \mathrm{~nm})$ of 1.1 . After induction at $16^{\circ} \mathrm{C}$ for $16 \mathrm{~h}$, the cells were collected and resuspended in buffer containing $25 \mathrm{mM}$ Tris- $\mathrm{HCl}$ (pH 8.0) and $150 \mathrm{mM} \mathrm{NaCl}$. Following further disruption by a homogenizer (JNBIO), cell debris was removed via centrifugation at 23,000 $\mathrm{g}$ for $1 \mathrm{~h}$. The supernatant was collected and loaded onto $\mathrm{Ni}^{2+}$-nitrilotriacetate affinity resin (Ni-NTA, Qiagen), followed by washing with $25 \mathrm{mM}$ Tris- $\mathrm{HCl}$ ( $\mathrm{pH}$ 8.0), $150 \mathrm{mM} \mathrm{NaCl}$, and $20 \mathrm{mM}$ imidazole. The AimR protein was eluted using a buffer containing $25 \mathrm{mM}$ Tris- $\mathrm{HCl}$ (pH 8.0) and $250 \mathrm{mM}$ imidazole. The eluted protein was further purified using anion-exchange chromatography (Source 15Q 10/100, GE Healthcare). The elution peak was subjected to size-exclusion chromatography (Superdex-200 Increase 10/300, GE Healthcare) in a buffer containing $25 \mathrm{mM}$ Tris- $\mathrm{HCl}$ (pH 8.0), $150 \mathrm{mM} \mathrm{NaCl}$, and $5 \mathrm{mM}$ dithiothreitol (DTT). The peak fractions were collected for crystallization. The AimR mutants were generated using a two-step PCR strategy and were subcloned into pET15b, overexpressed and purified in the same way as the wild-type protein. Following proteolytic removal of the hexahistidine ( $6 \times$ His) tag by drICE, the mutation proteins were purified using size-exclusion chromatography in a buffer containing $25 \mathrm{mM}$ Tris- $\mathrm{HCl}$ (pH 8.0) and $150 \mathrm{mM} \mathrm{NaCl}$ for biochemical assays.

\section{Crystallization}

For the apo form and peptide-bound AimR, the purified protein was concentrated to $\sim 270 \mu \mathrm{M}\left(\sim 12.5 \mathrm{mg} \mathrm{ml}^{-1}\right)$, incubated on ice for $30 \mathrm{~min}$ with or without the arbitrium peptide GMPRGA $(2.7 \mathrm{mM})$ (GLS Biochem). For the DNA-bound AimR, the purified protein was concentrated to $\sim 270 \mu \mathrm{M}\left(\sim 12.5 \mathrm{mg} \mathrm{ml}^{-1}\right)$, incubated on ice for $30 \mathrm{~min}$ with $276 \mu \mathrm{M} 31 \mathrm{bp}$ DNA fragment (77710-77740, 5' ACTTAAATATTAGGTTTTAATAACATCTAGT 3') and $5 \mathrm{mM} \mathrm{MgCl}_{2}$. All sample crystallized in hanging 
drops at $18{ }^{\circ} \mathrm{C}$ using a mixture of $1 \mu \mathrm{l}$ of the sample and $1 \mu \mathrm{l}$ of the crystallization buffer. Crystals of the apo form under the conditions in the presence of $0.1 \mathrm{M}$ sodium cacodylate ( $\mathrm{pH} 6.6), 11 \%$ polyethylene glycol 8000 , and $0.2 \mathrm{M}$ sodium chloride. The crystals of GMPRGA peptideAimR under the $0.1 \mathrm{M}$ sodium cacodylate (pH 6.1), 9\% polyethylene glycol $8000,0.2 \mathrm{M} \mathrm{NaBr}$, and $5 \mathrm{mM}$ DTT. The crystal of DNA-bound AimR was grown in $0.1 \mathrm{M}$ sodium cacodylate $(\mathrm{pH} 5.8)$ and $11 \%$ polyethylene glycol 4000. The crystals grew to full size in 3 or 4 days. They were flash-frozen in liquid nitrogen and cryoprotected with well buffer and $60 \%$ glycerol mixture (v:v $=1: 1)$, but the DNA binding form crystals were cryoprotected mixed with $40 \%$ glycerol $(\mathrm{v}: \mathrm{v}=1: 1)$.

\section{Data collection and structure determination}

All of the diffraction data were collected at the Shanghai Synchrotron Research Facility (SSRF) on beamline BL17U1 or BL19U1 and then integrated and processed using the XDS program ${ }^{27-29}$. Further data processing was performed using the CCP4 suite ${ }^{30}$. The structure of DNAbound AimR was determined through molecular replacement with the apo-form AimR (PDB ID:5XYB) as the search model using the program PHASER ${ }^{31}$. The DNAbound AimR structures were iteratively built using COOT and refined using the PHENIX program ${ }^{32,33}$. It is clear that a well-built model can be generated from the electron density of the AimR N-terminal residues 1-40. As we described, the diffraction data of apo-form AimR and peptide-bound form AimR were newly collected. Using NTD of DNA-bound AimR as the initial model, the Nterminal models of Apo-form AimR and peptide-bound AimR can be built. Similarly, COOT and PHENIX were applied to structural refinement. Data collection and structure refinement statistics are summarized in Table 1. All of the figures were generated using PyMOL (http:// www.pymol.org/).

\section{Electrophoretic mobility shift assay}

DNA probes were annealed using boiling water with FAM-labeled primers to generate the $37 \mathrm{bp}$ DNA fragment (77707-77743, 5' ATCACTTAAATATTAGGTT TTAATAACATCTAGTGAT $3^{\prime}$ ). The labeled probes $(5 \mathrm{nM})$ were incubated with $0.004,0.02,0.1$, and $0.5 \mu \mathrm{M}$ AimR proteins or peptide-bound AimR complex (molar ratio $=10: 1)$ in a buffer containing $25 \mathrm{mM}$ Tris- $\mathrm{HCl}(\mathrm{pH}$ 8.0), $5 \mathrm{mM} \mathrm{MgCl} 2,5 \mathrm{mM}$ DTT, $0.1 \mathrm{mg} \mathrm{ml}^{-1}$ BSA, $10 \%$ glycerol, $150 \mathrm{mM} \mathrm{NaCl}$, and $50 \mu \mathrm{g} \mathrm{ml}^{-1}$ salmon sperm DNA at $4{ }^{\circ} \mathrm{C}$ for $15 \mathrm{~min}$. The reactions were resolved on $8 \%$ native acrylamide gels (37.5:1 acrylamide:bis-acrylamide) in $0.5 \times$ Tris-Boric acid buffer at $150 \mathrm{~V}$ for $3 \mathrm{~h}$. Images of the gels were obtained using FLA5100 (Typhoon, Fuji, Japan).

\section{Growth dynamics of SPbeta-infected B. subtilis}

Overnight cultures of B. subtilis CU1065 and aimRoverexpressing strains were diluted 1:100 in LB medium and incubated at $28{ }^{\circ} \mathrm{C}$ with shaking until the suspension reached $\mathrm{OD}_{600}=0.1$. The bacteria were infected with the SPbeta phage or the SPbeta $\triangle$ aimR phage at MOI $=0.001$. The $\mathrm{OD}_{600}$ was measured every $30 \mathrm{~min}$ using a spectrophotometer (Jingke Instrument, 722N). All growth dynamics curves were drawn using Origin 8.0.

\section{Fluorescent dye conjugation}

The point mutation of AimR-V129C (C71S/C107S/ C213S/C275S/C304S/C347S/V129C) was generated with a standard PCR-based strategy and subcloned, overexpressed, and purified in the same way as the mutant proteins. The distance between two $\mathrm{Ca}$ atoms of V129 residues in peptide-bound AimR complex is $61.9 \AA$ and is shorten to $30.8 \AA$ in DNA-bound AimR complex that would produce discernible FRET efficiencies. Alexa Fluor $488 \quad \mathrm{C}_{5}$ maleimide (Thermo Fisher, A10254) and Cy5 maleimide (GE Healthcare, PA15131) $\left(R_{0}=52 \AA^{34}\right)$ were freshly dissolved in DMSO at $1 \mathrm{mM}$ concentration before conjugation. A desalting column (HiPrep 26/10, GE Healthcare) was used to exchange the buffer of AimR V129C containing $20 \mathrm{mM}$ phosphate, $\mathrm{pH} 7.4$ and $100 \mathrm{mM} \mathrm{NaCl}$, and the protein fraction was collected in premixed Alexa488 and Cy 5 dye. The molar ratio of the conjugation reaction of AimR V129C:Alexa488:Cy5 was 1:4:6. Conjugation was performed for $3 \mathrm{~h}$ at room temperature in the dark, and the mixture was then purified by a Source-Q column (GE Healthcare). The fraction of double-labeled protein that exhibited absorption at 280,493 , and $640 \mathrm{~nm}$ was simultaneously collected for smFRET data collection.

\section{Single-molecule FRET data collection and analysis}

The smFRET data collection and analysis were performed as previously described ${ }^{35}$. In brief, an A1 confocal microscope (Nikon, Japan) coupled to two picosecond pulsed diode laser heads (LDH-P-C-485B and LDH-P-C640B, PicoQuant, Germany) and two SPCM-AQRH detectors (Excelitas, Canada) was used for fluorescence excitation and emission detection. A $60 \times$ water immersion objective (WI 60×, NA 1.20, Nikon, Japan) was used for confocal laser microscopy, and the pinhole size was set at approximately $100 \mu \mathrm{m}$. The laser power before the objective was set at $\sim 100 \mu \mathrm{W}$ for the $485-\mathrm{nm}$ laser and $\sim 35 \mu \mathrm{W}$ for the 640-nm laser. Donor emission was filtered with an ET550/50 $\mathrm{m}$ bandpass (Chroma), and acceptor emission was filtered with an ET700/75 $\mathrm{m}$ bandpass (Chroma), before being focused onto the two SPCMAQRH detectors. A pulsed interleaved excitation (PIE) 
scheme at a repetition of $32 \mathrm{MHz}$ was employed for data collection to exclude the emitted photons that resulted from donor only or acceptor only species ${ }^{36}$.

The smFRET measurements were performed at $25^{\circ} \mathrm{C}$ in pH 7.4 buffer containing $20 \mathrm{mM}$ phosphate, $100 \mathrm{mM} \mathrm{NaCl}$, and $0.01 \%(\mathrm{v} / \mathrm{v})$ Tween 20, with additional $1 \mathrm{mM}$ ascorbic acid and $1 \mathrm{mM}$ methylviologen for photobleaching and blinking minimization ${ }^{37}$. A concentration of $\sim 150 \mathrm{pM}$ of dye-labeled protein was used for data collection. The arbitrium peptide (GMPRGA, GLS Biochem), an unrelated peptide (GFGHA, GLS Biochem) and $37 \mathrm{bp}$ DNA (77707-77743， 5' ATCACTTAAATATTAGGTTTTAATAACATCTAGTGAT $3^{\prime}$ ) were prepared as stock solutions in a buffer containing $20 \mathrm{mM}$ phosphate, $\mathrm{pH} 7.4$ and $100 \mathrm{mM} \mathrm{NaCl}$ and were mixed with AimR V129C prior to each experiment to achieve the desired concentrations. The smFRET data were typically collected for $\sim 1 \mathrm{~h}$. Photon time traces were binned with a $1 \mathrm{~ms}$ width, and 4-9 counts/bin were used as the threshold for burst searching. The burst searching process was performed using a handwritten script, and a minimum of 25 total photon counts was defined as a burst event. The exact FRET efficiencies were calculated based on our calibrated parameters for the instrument and fluorophores, and the FRET efficiency distribution was analyzed with a multi-Gaussian mixture using a handwritten script ${ }^{35}$.

\section{Intermolecular crosslinking of AimR}

The point mutation AimR-N166C (C71S/C107S/ C213S/C275S/C304S/C347S/N166C) was generated with a standard PCR-based strategy and subcloned, overexpressed, and purified in the same way as the mutant protein. After gel filtration, the peak fractions were collected for further characterization. The intermolecular crosslinking of AimR, targeting Cys166 in two adjacent protomers, was catalyzed by $2 \mathrm{mM}$ freshly prepared ophenanthroline copper complex ${ }^{38,39}$. The AimR-N166C protein at approximately $1 \mathrm{mg} / \mathrm{ml}$ was mixed with the GMPRGA peptide and DNA for $15 \mathrm{~min}$. Then, these components were mixed with catalyst at the indicated concentrations and incubated at room temperature for $30 \mathrm{~min}$. Reducing reagents were avoided in each step. The same amount of protein solution was incubated with $5 \mathrm{mM}$ DTT at room temperature for $30 \mathrm{~min}$ as a control. For the EMSA assay, the mutant protein was treated with $2 \mathrm{mM}$ o-phenanthroline copper complex and further purified through gel filtration (Superdex-200 10/300, GE Healthcare) in buffer containing $25 \mathrm{mM}$ Tris- $\mathrm{HCl}(\mathrm{pH}$ 8.0) and $150 \mathrm{mM} \mathrm{NaCl}$.

\section{Acknowledgements}

The authors are grateful to the staff of the BL17U1/BL19U1/BL19U2 beamline of the National Center for Protein Sciences Shanghai (NCPSS) at the Shanghai Synchrotron Radiation Facility for assistance during data collection and the research associates at the Centre for Protein Research, Huazhong Agricultural
University, for technical support. This work was supported by funds from the National Key R\&D Program of China (2018YFA0507700 for Ping Yin and Zhu Liu), the National Natural Science Foundation of China (Grant number 81601742 for Tingting Zou), and the Fundamental Research Funds for the Central Universities (Program No. 2662014BQ028 for Tingting Zou, and 2662017PY031 for Ping Yin).

\section{Author details}

${ }^{1}$ National Key Laboratory of Crop Genetic Improvement and National Centre of Plant Gene Research, Huazhong Agricultural University, Wuhan 430070 Hubei, China. ${ }^{2}$ CAS Key Laboratory of Magnetic Resonance in Biological Systems, State Key Laboratory of Magnetic Resonance and Atomic Molecular Physics, and National Center for Magnetic Resonance at Wuhan, Wuhan Institute of Physics and Mathematics, Chinese Academy of Sciences, Wuhan 430071 Hubei Province, China. ${ }^{3}$ College of Life Science and Technology, Huazhong Agricultural University, Wuhan 430070 Hubei, China

\section{Author contributions}

Z.G., K.P., D.Z., C.T., P.Y., Z.L., and T.Z. designed the project and analyzed data. Z. G. and K.P. contributed to protein crystallization and structure determination. K. $P$. and Y.Z. performed EMSA, sample preparation, and intermolecular crosslinking assays. J.W., Y.C., X.Z., and X.S. performed the in vivo experiments. Z.L. performed smFRET experiments and analyses. Z.G., Z.L., and T.Z. wrote the manuscript with support from all authors.

\section{Data availability}

Atomic coordinates and structure factors of the apo form AimR, peptidebound form AimR, and DNA-bound form AimR have been deposited to Protein Data Bank under accession numbers 6JG5, 6JG9, and 6JG8, respectively.

Conflict of interest

The authors declare that they have no conflict of interest.

\section{Publisher's note}

Springer Nature remains neutral with regard to jurisdictional claims in published maps and institutional affiliations.

Supplementary Information accompanies the paper at (https://doi.org/ 10.1038/s41421-019-0101-2).

Received: 4 April 2019 Revised: 28 April 2019 Accepted: 5 May 2019 Published online: 28 May 2019

\section{References}

1. Dunny, G. M. \& Leonard, B. A. B. Cell-cell communication in Gram-positive bacteria. Annu. Rev. Microbiol. 51, 527-564 (1997).

2. Bassler, B. L. Small talk. Cell-to-cell communication in bacteria. Cell 109, $421-424(2002)$

3. Waters, C. M. \& Bassler, B. L. Quorum sensing: cell-to-cell communication in bacteria. Annu. Rev. Cell Dev. Biol. 21, 319-346 (2005).

4. Bassler, B. L. \& Losick, R. Bacterially speaking. Cell 125, 237-246 (2006).

5. Monnet, V., Juillard, V. \& Gardan, R. Peptide conversations in Gram-positive bacteria. Crit. Rev. Microbiol. 42, 339-351 (2016).

6. Monnet, V. \& Gardan, R. Quorum-sensing regulators in Gram-positive bacteria: 'cherchez le peptide'. Mol. Microbiol. 97, 181-184 (2015).

7. Whiteley, M., Diggle, S. P. \& Greenberg, E. P. Progress in and promise of bacterial quorum sensing research. Nature 551, 313-320 (2017).

8. Do, H. \& Kumaraswami, M. Structural mechanisms of peptide recognition and allosteric modulation of gene regulation by the RRNPP family of quorumsensing regulators. J. Mol. Biol. 428, 2793-2804 (2016).

9. Perez-Pascual, D., Monnet, V. \& Gardan, R. Bacterial cell-cell communication in the host via RRNPP peptide-binding regulators. Front. Microbiol. 7, 706 (2016).

10. Neiditch, M. B., Capodagli, G. C., Prehna, G. \& Federle, M. J. Genetic and structural analyses of RRNPP intercellular peptide signaling of Gram-positive bacteria. Annu. Rev. Genet. 51, 311-333 (2017).

11. Erez, Z. et al. Communication between viruses guides lysis-lysogeny decisions. Nature 541, 488-493 (2017). 
12. Davidson, A. R. Virology: phages make a group decision. Nature $\mathbf{5 4 1}, \mathbf{4 6 6 - 4 6 7}$ (2017).

13. Hynes, A. P. \& Moineau, S. Phagebook: the social network. Mol. Cell 65 963-964 (2017).

14. Ofir, G. \& Sorek, R. Contemporary phage biology: from classic models to new insights. Cell 172, 1260-1270 (2018).

15. Wang, Q. et al. Structural basis of the arbitrium peptide-AimR communication system in the phage lysis-lysogeny decision. Nat. Microbiol. 3, 1266-1273 (2018).

16. Dou, C. et al. Structural and functional insights into the regulation of the lysis-lysogeny decision in viral communities. Nat. Microbiol. 3, 1285-1294 (2018).

17. Zhen, X. et al. Structural basis of AimP signaling molecule recognition by AimR in Spbeta group of bacteriophages. Protein Cell. https://doi.org/10.1007/ s13238-018-0588-6 (2018).

18. Trinh, J. T. \& Zeng, L. Structure regulates phage lysis-lysogeny decisions. Trends Microbiol. 27, 3-4 (2019).

19. Zouhir, S. et al. Peptide-binding dependent conformational changes regulate the transcriptional activity of the quorum-sensor NprR. Nucleic Acids Res. 41, 7920-7933 (2013)

20. Shi, $K$. et al. Structure of peptide sex pheromone receptor PrgX and PrgX pheromone complexes and regulation of conjugation in Enterococcus faecalis. Proc. Natl Acad. Sci. USA 102, 18596-18601 (2005).

21. Grenha, R. et al. Structural basis for the activation mechanism of the PlcR virulence regulator by the quorum-sensing signal peptide PapR. Proc. Natl Acad. Sci. USA 110, 1047-1052 (2013).

22. Declerck, N. et al. Structure of PlcR: insights into virulence regulation and evolution of quorum sensing in Gram-positive bacteria. Proc. Natl Acad. Sci. USA 104, 18490-18495 (2007).

23. Talagas, A. et al. Structural insights into Streptococcal competence regulation by the cell-to-cell communication system ComRS. PLoS Pathog. 12, e1005980 (2016).

24. Gallego Del Sol, F., Penades, J. R. \& Marina, A. Deciphering the molecular mechanism underpinning phage arbitrium communication systems. Mol. Cell. 74, 59-72 (2019).
25. Deng, Y. et al. Apnl, a transmembrane protein responsible for subtilomycin immunity, unveils a novel model for lantibiotic immunity. Appl. Environ. Microbiol. 80, 6303-6315 (2014).

26. Zahler, S. A., Korman, R. Z., Rosenthal, R. \& Hemphill, H. E. Bacillus subtilis bacteriophage SPbeta: localization of the prophage attachment site, and specialized transduction. J. Bacteriol. 129, 556-558 (1977).

27. Wang, Q. S. et al. The macromolecular crystallography beamline of SSRF. Nucl. Sci. Tech. 26, 12-17 (2015).

28. Wang, Q.-S. et al. Upgrade of macromolecular crystallography beamline BL17U1 at SSRF. Nucl. Sci. Tech. 29, 68 (2018).

29. Kabsch, W. Xds. Acta Crystallogr. D Biol. Crystallogr. 66, 125-132 (2010).

30. Winn, M. D. et al. Overview of theCCP4 suite and current developments. Acta Crystallogr. D Biol. Crystallogr. 67, 235-242 (2011).

31. McCoy, A. J. et al. Phaser crystallographic software. J. Appl. Crystallogr. 40 658-674 (2007).

32. Adams, P. D. et al. PHENIX: a comprehensive Python-based system for macromolecular structure solution. Acta Crystallogr. D Biol. Crystallogr. 66, 213-221 (2010).

33. Emsley, P. \& Cowtan, K. Coot: model-building tools for molecular graphics. Acta Crystallogr. D Biol. Crystallogr. 60, 2126-2132 (2004).

34. Kalinin, S. et al. A toolkit and benchmark study for FRET-restrained highprecision structural modeling. Nat. Methods 9, 1218-1225 (2012).

35. Dong, $X$. et al. Ubiquitin $\mathbf{S} 65$ phosphorylation engenders a $\mathrm{pH}$ sensitive conformational switch. Proc. Natl Acad. Sci. USA 114 6770-6775 (2017).

36. Muller, B. K., Zaychikov, E., Brauchle, C. \& Lamb, D. C. Pulsed interleaved excitation. Biophys. J. 89, 3508-3522 (2005).

37. Vogelsang, J. et al. A reducing and oxidizing system minimizes photobleaching and blinking of fluorescent dyes. Angew. Chem. 47, 5465-5469 (2008).

38. Ren, R. et al. PROTEIN STRUCTURE. Crystal structure of a mycobacterial Insig homolog provides insight into how these sensors monitor sterol levels. Science 349, 187-191 (2015).

39. Kobashi, K. Catalytic oxidation of sulfhydryl groups by o-phenanthroline copper complex. Biochim. Biophys. Acta 158, 239-245 (1968). 